\title{
Inequity in access to bDMARD care and how it influences disease outcomes across countries worldwide: results from the METEOR-registry
}

\author{
Sytske Anne Bergstra, ${ }^{1}$ Jaime C Branco, ${ }^{2,3}$ David Vega-Morales, ${ }^{4}$ \\ Karen Salomon-Escoto, ${ }^{5}$ Nimmisha Govind ${ }^{6}$ Cornelia F Allaart, ${ }^{1}$ \\ Robert B M Landewé 7,8
}

\begin{abstract}
Handling editor Josef $S$
Smolen

- Additional material is published online only. To view please visit the journal online (http://dx.doi.org/10.1136/ annrheumdis-2018-213289).
\end{abstract}

For numbered affiliations see end of article.

Correspondence to Sytske Anne Bergstra, Department of Rheumatology Leiden University Medical Center, Leiden 2333 ZA, The Netherlands;

s.a.bergstra@|umc.nl

Received 22 February 2018 Revised 18 June 2018 Accepted 19 June 2018 Published Online First 6 July 2018

\section{ABSTRACT \\ Objective To establish in a global setting the relationships between countries' socioeconomic status (SES), measured biological disease modifying antirheumatic drug (bDMARD)-usage and disease outcomes. To assess if prescription and reimbursement rules and generic access to medication relates to a countries' bDMARD-usage.}

Methods Data on disease activity and drug use from countries that had contributed at least 100 patients were extracted from the METEOR database. Mean disease outcomes of all available patients at the final visit were calculated on a per-country basis. A questionnaire was sent to at least two rheumatologists per country inquiring about DMARD-prices, access to treatment and valid regulations for prescription and reimbursement.

Results Data from 20379 patients living in 12 different countries showed that countries' SES was positively associated with measured disease activity (meanDAS28), but not always with physical functioning (HAQ-score). A lower country's SES, stricter rules for prescription and reimbursement of bDMARDs as well as worse affordability of bDMARDs were associated with lower bDMARD-usage. bDMARD-usage was negatively associated with disease activity (although not with physical functioning), but the association was moderate at best.

Conclusions Disease activity in patients with rheumatoid arthritis as well as bDMARD-usage varies across countries worldwide. The (negative) relationship between countries' bDMARD-usage and level of disease activity is complex and under the influence of many factors, including - but not limited to-countries' SES, affordability of bDMARDs and valid prescription and reimbursement rules for bDMARDs.

\section{INTRODUCTION}

Earlier diagnosis and treatment, the implementation of treat-to-target and new treatment options, including biological disease modifying antirheumatic drugs (bDMARDs), have improved treatment and prognosis of patients with rheumatoid arthritis (RA) tremendously. ${ }^{1-3}$ Since many of these treatments are costly, patients across the world may not benefit similarly. Indeed, a lower level of welfare has been associated with higher disease activity in patients with RA in the past. ${ }^{4}$
One of the potentially critical factors is poorer access to bDMARDs. ${ }^{25}$ Current recommendations advise starting bDMARDs after a first conventional synthetic disease modifying antirheumatic drug (csDMARD) strategy has failed. ${ }^{5}$ But such a strategy may not be feasible in greater parts of the world. In many countries, there are various restrictions in the prescription and reimbursement of bDMARD. ${ }^{6-9}$ Within Europe, differences in socioeconomic welfare are associated with differences in prescription and reimbursement of bDMARDs. ${ }^{6}{ }^{10}$ Stricter prescription rules and reimbursement criteria of bDMARDs may result in more infrequent use of bDMARDs and in worse health outcomes. ${ }^{69}$ To date, only one study, limited to European countries, has been performed that has taken into account all currently available bDMARDs. ${ }^{6}$

We have investigated here daily-practice data regarding bDMARD-use in different countries worldwide and have assessed if a lower country's socioeconomic status (SES) is associated with worse clinical outcomes and lower bDMARD-usage. We have also assessed if countries' bDMARD-usage was associated with stricter prescription and reimbursement rules and worse access to medication.

\section{METHODS}

\section{Data selection}

Disease activity and medication use in patients with RA in various countries on various treatments were extracted from the METEOR registry, an international database capturing data of daily clinical practice of patients with a clinical diagnosis of RA. ${ }^{11}$ Visits were unprotocolled and data were gathered retrospectively and anonymously; hence no informed consent was needed. We selected visits after 1-1-2000 from countries that had included at least 100 patients with follow-up data available (supplementary file 1).

Missing data on disease activity and function (HAQ-score) were imputed using multivariate normal imputation (30 imputations). ${ }^{12}$ For each country, average DAS2 8 and HAQ and the proportion of patients in DAS28-remission (DAS28 <2.6) were calculated by taking the average of all patients at the last available visit. Furthermore, the proportion of patients that ever used a biological was calculated per country. 


\begin{tabular}{|c|c|c|c|c|}
\hline \multicolumn{5}{|c|}{ Composite score clinical criteria start of bDMARDs } \\
\hline & 0 & 1 & 2 & \\
\hline $\begin{array}{l}\text { Is there any } \\
\text { requirement } \\
\text { for disease } \\
\text { duration? }\end{array}$ & $\begin{array}{l}\text { Any } \\
\text { requirement }\end{array}$ & No requirement & NA & \\
\hline $\begin{array}{l}\text { Number of } \\
\text { DMARDs to be } \\
\text { failed }\end{array}$ & $>2$ & 2 & $<2$ & \\
\hline Level of DAS28 & $>3.2$ & $\leq 3.2$ & No requiremen & \\
\hline \multicolumn{5}{|c|}{ Composite score access to medication } \\
\hline & 0 & 1 & 2 & 3 \\
\hline $\begin{array}{l}\text { Number of } \\
\text { reimbursed } \\
\text { bDMARDs }\end{array}$ & 0 & $1-5$ & $6-7$ & 8 \\
\hline $\begin{array}{l}\text { Average annual } \\
\text { price of all } \\
\text { reimbursed } \\
\text { bDMARDs }\end{array}$ & $\begin{array}{l}\text { Highest } \\
\text { quartile }\end{array}$ & Second quartile & Third quartile & Lowest quartile \\
\hline $\begin{array}{l}\text { Average score } \\
\text { on the six } \\
\text { acceptability } \\
\text { questions }\end{array}$ & $\begin{array}{l}\text { Highest } \\
\text { quartile }\end{array}$ & Second quartile & Third quartile & Lowest quartile \\
\hline
\end{tabular}

bDMARDs, biological disease modifying antirheumatic drugs; NA, not applicable.

\section{Questionnaire}

Per participating country, preferably in the region of data collection, at least two rheumatologists answered a questionnaire, based on questionnaires used by Putrik et al. ${ }^{13}$ In case of disagreement between rheumatologists, they were contacted by email, and if necessary additional rheumatologists were contacted to also complete the questionnaire. The questionnaire included questions about availability and affordability of DMARDs, acceptability, reimbursement and prescription rules (online supplementary file 2). Drug prices provided in local currency were converted into euros or international dollars at the rate of 10-1-2017. For each DMARD, we took the lowest available price. When all questions were processed, a preliminary report was sent to all collaborators, to check correctness of the data.

\section{Outcome measures}

Based on the questionnaire results, two composite scores were calculated: a composite score for clinical eligibility criteria for the start of bDMARDs, based on three questions from the questionnaire and with an optimum score of 5 indicating 'least requirements', and a composite score for access to medication, based on questions on availability, affordability and acceptability, with an optimum score of 9 indicating 'highest level of access' (table 1). ${ }^{613}$

In addition, we calculated the average annual national price of the most frequently used csDMARDs and bDMARDs. These included the csDMARDs methotrexate, sulfasalazine, hydroxychloroquine and leflunomide and prednisone and the bDMARDs etanercept, adalimumab, infliximab, rituximab, certolizumab, tocilizumab, abatacept and golimumab. For each DMARD a most common treatment scheme was used to calculate the costs for 1 year usage (the annual national price, averaged over the first two treatment years). ${ }^{13}$ Furthermore, an affordability index for bDMARDs was constructed by dividing the average annual national price for all bDMARDs by the gross domestic product. ${ }^{13}$ All medication prices reflect official manufacturer's prices per country, not taking into account local or temporary discounts, which fall beyond the scope of this study.

The gross domestic product (GDP) per capita, the household-net-adjusted-disposable-income, the health-expenditure-per-capita in international dollars and the minimum wage per year in US\$ were derived from web-based sources. ${ }^{14-16}$ Data regarding the minimum wage and the average price for csDMARDs and bDMARDs were used to calculate the days to work at the minimum wage to cover 30 days of treatment with a csDMARD or bDMARD. ${ }^{13}$

\section{Statistical analyses}

At a country level, associations between several indicators of SES, clinical outcomes, medication use, access to medication and prescription and reimbursement rules were assessed using univariable linear regression analyses. Since analyses were performed at a country level and the number of included countries was limited, multivariable regression analyses were not performed. Regression results for the GDP per capita, the household-net-adjusted-disposable-income and the health-expenditure-per-capita were assessed per 10000 Intl\$.

To assess whether analysing data at a patient level where possible would change the outcomes, we performed a sensitivity analysis using linear mixed modelling for continuous outcomes and generalised linear mixed modelling for dichotomous outcomes, with patients nested within countries and a random intercept at the country level. All analyses were performed using Stata SE14 (Stata).

\section{RESULTS}

\section{Country and database characteristics}

Twelve countries with 20379 patients were analysed: USA (state of Massachusetts), Mexico, South Africa, Japan, Brazil, UK, Spain, Ireland, Portugal, France, India (state of Maharashtra) and the Netherlands. Data from Qatar and Italy were ultimately excluded from the analyses, since only one rheumatologist in Qatar was available to complete the questionnaire and data from Italy were mainly derived from a biologics register. The number of questionnaire responders per country is listed in online supplementary file 3 .

Table 2 presents average country and database characteristics. Additional patient characteristics are presented in online supplementary file 4 . The number of patients per country ranged from 123 (Spain) to 7749 (India) and the number of patients ever using a bDMARD ranged from 0.9\% (South Africa) to $75 \%$ (Ireland). There were important differences in DAS28scores and HAQ-scores across countries. Overall, and expectedly, DAS28 was positively associated with HAQ-score, except in India, where the average DAS28 was highest but the average HAQ-score was among the lowest of all countries. As expected, there were important differences in SES between countries, reflected-for example-by differences in GDP per capita (ranging from Intl\$5733 in India to Int1\$61378 in Ireland) and by large differences in the country's number of days required to work at the minimum wage to cover 30 days of treatment with a bDMARD (ranging from 562 days in India to only 19 days in France).

Average annual medication prices also substantially differed between countries (figure 1). For bDMARDs, drug prices (Intl\$) in the USA (highest) were 5.9 times higher than in France (lowest) and for csDMARDs, drug prices in the USA (highest) were 14.7 times higher than in the Netherlands (lowest). 
Table 2 Baseline characteristics per country

\begin{tabular}{|c|c|c|c|c|c|c|}
\hline & India & South Africa & Brazil & Mexico & Portugal & Spain \\
\hline \multicolumn{7}{|l|}{ Country characteristics } \\
\hline Population (×1 000000$)$ & 1311.1 & 10.4 & 207.8 & 127.0 & 10.4 & 46.4 \\
\hline GDP per capita (Int|\$) & 5733 & 12393 & 14533 & 16490 & 26549 & 32219 \\
\hline Minimum wage per year (US\$) & 778 & 2197 & 3660 & 1438 & 8384 & 10365 \\
\hline Household net adjusted disposable income (Int|\$) & NA & 21481 & 19882 & 33164 & 31649 & 30776 \\
\hline Health expenditure per capita (Int|\$) & 301 & 1405 & 1639 & 1753 & 3338 & 3717 \\
\hline Days work at minimum wage to cover 30 days treatment bDMARD & 562 & 160 & 223 & 431 & 53 & 49 \\
\hline Days work at minimum wage to cover 30 days treatment csDMARD & 2.2 & 4.9 & 3.3 & 7.4 & 0.7 & 0.7 \\
\hline Mean price bDMARDs year/GDP per capita & 8.45 & 1.93 & 3.07 & 3.07 & 0.84 & 0.70 \\
\hline Composite score access to medication & 3 & 3 & 5 & 1 & 6 & 5 \\
\hline Composite score clinical criteria & 4 & 1 & 1 & 4 & 5 & 4 \\
\hline \multicolumn{7}{|l|}{ Database characteristics } \\
\hline Number of patients & 7749 & 670 & 189 & 1191 & 3874 & 123 \\
\hline Mean time since diagnosis at last recorded visit (days) & 1304 & 577 & 4900 & 2898 & 5599 & 1327 \\
\hline$\%$ patients bDMARD use & 0.95 & 0.90 & 19.6 & 9.0 & 44.5 & 16.3 \\
\hline Mean last DAS28 & 5.1 & 4.2 & 4.2 & 4.0 & 3.5 & 3.3 \\
\hline$\%$ patients in DAS28-remission & 2.3 & 19.9 & 17.0 & 20.9 & 32.4 & 42.7 \\
\hline \multirow[t]{2}{*}{ Mean last $\mathrm{HAQ}$} & 0.67 & 1.27 & 1.26 & 0.71 & 1.05 & 0.55 \\
\hline & France & Japan & UK & Netherlands & USA & Ireland \\
\hline \multicolumn{7}{|l|}{ Country characteristics } \\
\hline Population (×1 000000$)$ & 66.5 & 127.0 & 65.1 & 16.9 & 321.4 & 4.64 \\
\hline GDP per capita (Int|\$) & 37775 & 37872 & 38509 & 46354 & 52704 & 61378 \\
\hline Minimum wage per year (US\$) & 19886 & 12269 & 21793 & 20673 & 15080 & 20967 \\
\hline Household net adjusted disposable income (Int|\$) & 34092 & 30031 & 31724 & 31685 & 41071 & 25629 \\
\hline Health expenditure per capita (Int|\$) & 5681 & 4070 & 4678 & 6499 & 9403 & 4730 \\
\hline Days work at minimum wage to cover 30 days treatment bDMARD & 19 & 39 & 32 & 26 & 171 & 48 \\
\hline Days work at minimum wage to cover 30 days treatment csDMARD & 0.3 & 1.8 & 0.6 & 0.2 & 5.4 & 0.4 \\
\hline Mean price bDMARDs year/GDP per capita & 0.37 & 0.44 & 0.69 & 0.42 & 1.55 & 0.62 \\
\hline Composite score access to medication & 9 & 4 & 5 & 6 & 4 & 4 \\
\hline Composite score clinical criteria & 4 & 5 & 2 & 4 & 5 & 4 \\
\hline \multicolumn{7}{|l|}{ Database characteristics } \\
\hline Number of patients & 161 & 309 & 1291 & 3330 & 803 & 689 \\
\hline Mean time between diagnosis and last visit (days) & 5375 & 2503 & 3256 & 3181 & 3513 & 3921 \\
\hline$\%$ patients bDMARD use & 60.2 & 50.5 & 14.7 & 28.2 & 48.6 & 75.0 \\
\hline Mean last DAS28 & 2.5 & 3.2 & 3.9 & 3.2 & 3.6 & 3.8 \\
\hline$\%$ patients in DAS28-remission & 61.5 & 38.2 & 26.0 & 39.1 & 30.5 & 28.8 \\
\hline Mean last $\mathrm{HAQ}$ & 0.61 & 0.59 & 1.29 & 0.85 & 0.67 & 0.85 \\
\hline
\end{tabular}

'Number of patients' indicates the number of patients with $>1$ available visit. '\% patients bDMARD use' indicates the number of patients using a biological DMARD during at least one visit. 'Mean last DAS28' and 'mean last HAQ' are the DAS28 and HAQ at the last available visit in the database.

bDMARD, biological disease modifying antirheumatic drug; cSDMARD, conventional synthetic disease modifying antirheumatic drug; GDP, gross domestic product; Int|\$, international dollar; NA, not available.

\section{Countries' SES and clinical outcomes}

We first assessed if a lower SES was associated with worse clinical outcomes, by testing associations between GDP per capita and DAS28. Indeed, patients in countries with a higher GDP per capita had a lower average DAS28 and a higher proportion of them were in DAS28-remission (DAS28 lower by $\beta$ (95\% CI) $-0.32(-0.41 ;-0.021)$ and an additional $4.2(0.14 ; 8.26)$ per cent of patients in DAS28-remission for every $10000 \mathrm{Intl} \$$ additional GDP). The effect was less prominent in the USA and Ireland, both countries with the highest GDP per capita (figure 2A,C).

Then, we factored drug-prices into the 'model' by testing the association between the number of days needed to work at the minimum wage in order to afford 30 days of treatment with a bDMARD. Now the association was largely driven by two low-GDP countries (Mexico and India) (figure 2B,D) that yet have among the highest drug prices relative to the income. In most other countries, DAS28 and remission percentages were only slightly higher with each extra working day needed to afford bDMARDs: DAS28 higher by $\beta(95 \% \mathrm{CI}) 0.026$ (0.012 to 0.041$)$ and $-0.052(-0.084$ to -0.020$)$ less patients in DAS28-remission per additional minimal wage day required to afford 30 days bDMARDs.

Finally, we tested health-expenditures-per-capita as well as household's-net-adjusted-disposable income as proxies for SES and assessed the associations with DAS28. In general, the effects were similar: mean DAS28 was $-1.52(-2.8$ to -0.25$)$ points lower for every additional $10000 \mathrm{IntI} \$$ health-expenditure-per-capita, which culminated into 29.2 (1.91 to 56.6) per cent more patients in DAS28-remission. Such effects were not found for household's net-adjusted disposable income (data not shown). 

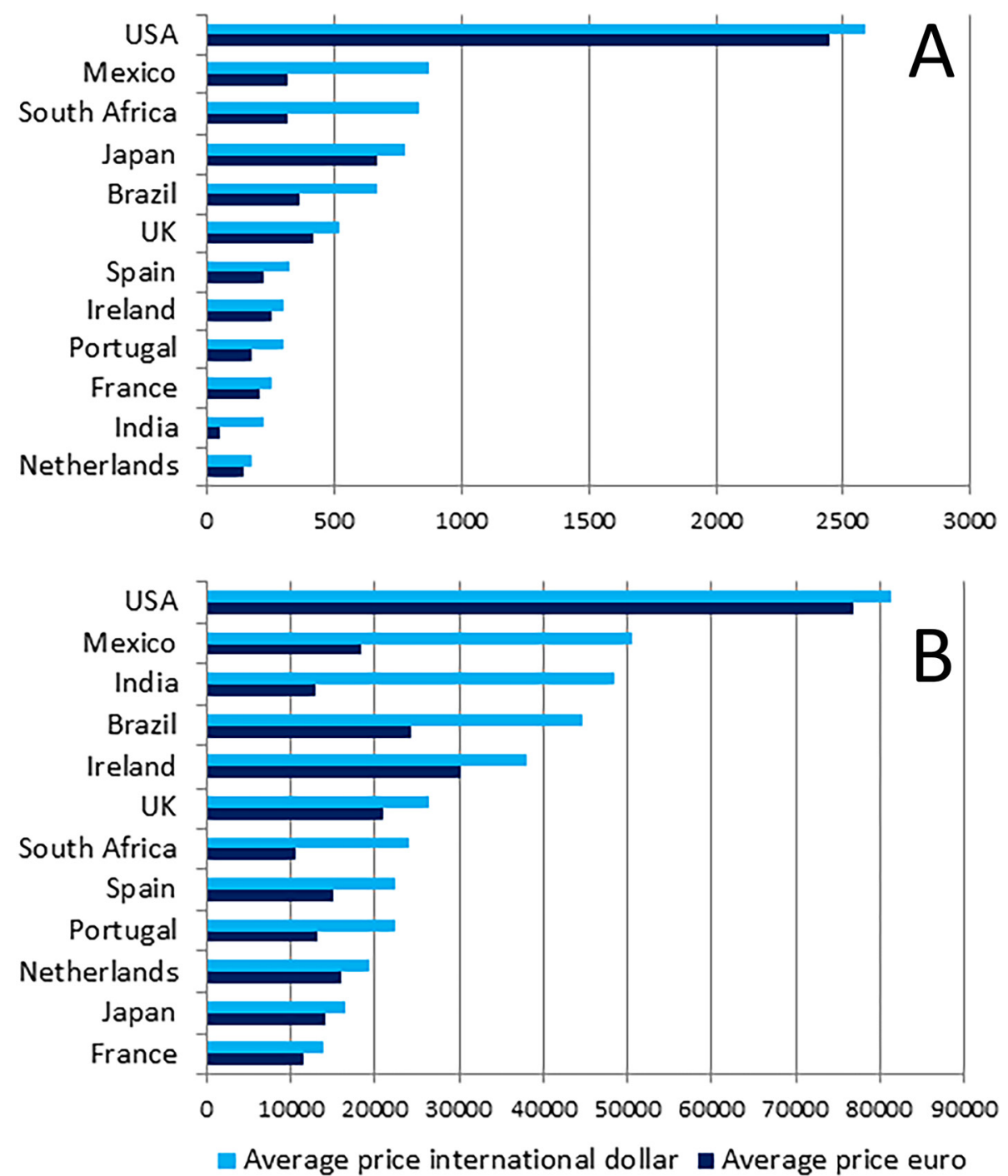

Figure 1 Average annual price for csDMARDs (A) and bDMARDs (B) per country in international dollars (light blue) and in euros (dark blue), prices first quarter 2017. bDMARDs, biological disease modifying antirheumatic drugs.

Overall, patients with RA from low-GDP-countries-on a per-capita basis-appear to have a higher DAS28 than patients from high-GDP-countries, regardless of countries' drug prices. It may be that in some countries drug-prices may mitigate the effects of SES on RA outcomes (drug prices were for instance importantly lower in Brazil and South Africa).

For HAQ-score, however, the associations with all indicators of SES were less clear: for example, $-0.031(-0.13$ to 0.064$)$ lower HAQ per 10000 Intl\$ increase in GDP per capita and $0.000034(-0.00091$ to 0.00098$)$ higher HAQ per additional minimal wage day required to afford 30 days bDMARDs.

\section{SES and bDMARD-usage}

It is attractive to assume that the inverse association between SES and DAS28 is mediated by the countries' bDMARD use (or: RA care in high-income countries is better since these can afford bDMARDs). We have sought evidence to underscore this assumption. First, we assessed whether SES was associated with bDMARD-usage per country. Indeed, a statistically significant association was found between GDP per capita and the proportion bDMARD-usage (11.2 (4.82 to 17.5$)$, figure $3 \mathrm{~A}$ ), indicating that per additional 10000 Intl\$ GDP per capita an additional $11 \%$ of patients used a bDMARD.
When taking drug-prices into account, the picture is more obscure. Although in Mexico and India bDMARD-usage was lowest, in the countries with highest GDP per capita, bDMARDusage was highly variable (ranging from close to $10 \%$ in the UK to $75 \%$ in Ireland), (figure $3 \mathrm{~A}, \beta(95 \% \mathrm{CI})-0.080(-0.16$ to $0.0021)$ ). This suggests that GDP and drug prices and other mechanisms (such as limitative regulations for reimbursement) determine bDMARD-usage.

\section{bDMARD-usage and clinical outcomes}

It is questionable, however, if a higher percentage of bDMARDusage translates automatically into better disease outcomes. We assessed whether bDMARD-usage across countries are associated with clinical outcomes. Indeed we found a statistically significant relationship between a country's proportion of bDMARD-usage and DAS28 or proportion of patients in DAS28-remission (figure 4A,B). DAS28 was $-0.14(-0.28$ to -0.0054$)$ point lower and $2.8 \%(-0.13$ to 5.8$)$ more patients achieved DAS28-remission, for every $10 \%$ increase in proportion of patients using a bDMARD. However, bDMARD-usage was not associated with better functional ability $(-0.024$ $(-0.091$ to 0.042$)$ lower HAQ-score for every $10 \%$ increase in bDMARD-usage). 

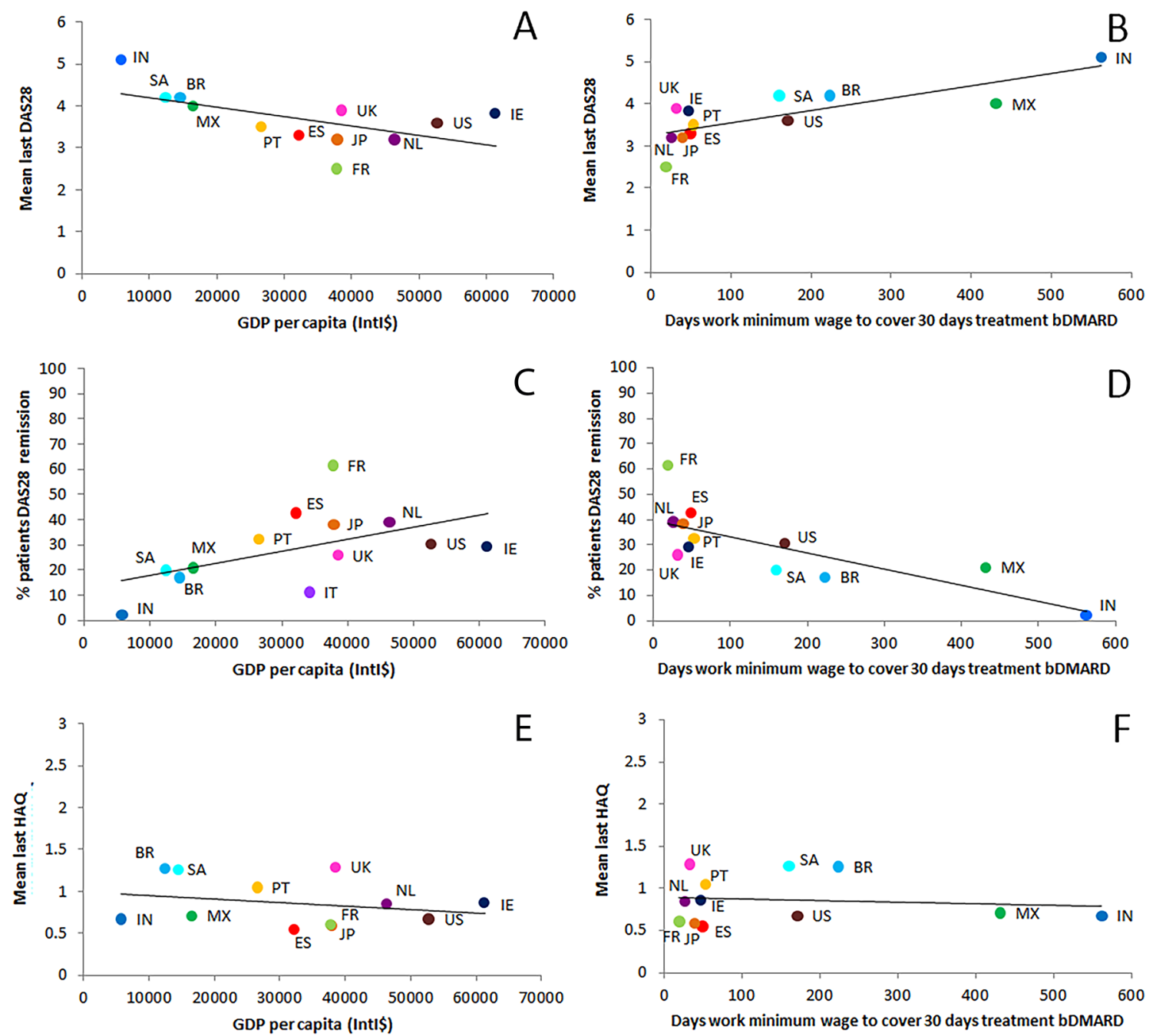

Figure 2 Associations between 'GDP per capita (Int|\$)' and 'days to work at the minimum wage to cover 30 days of treatment with a bDMARD' with clinical outcomes per country. bDMARDs, biological disease modifying antirheumatic drugs; BR, Brazil; ES, Spain, FR, France; GDP, gross domestic product; IE, Ireland; IN, India; JP, Japan; MX, Mexico; NL, Netherlands; PT, Portugal; SA, SouthAfrica.

\section{Prescription and reimbursement rules, access to medication and bDMARD-usage}

Since bDMARD-usage is not only influenced by a country's SES, it was subsequently assessed whether the stringency of prescription and reimbursement rules and 'access to medication' were associated with proportion of bDMARD-usage.

We found that bDMARD-usage is less if limitative regulations are stricter: 8.5 (-2.7 to 19.8) per cent more bDMARD use per point increase (ie, fewer limitations) in clinical criteria score and a trend $(5.9(-2.0$ to 13.8$))$ that better access to bDMARD-care led to more bDMARD-usage (figure 4D,E).

This shows that the previous relationship found between a country's SES and quality of RA care measured as a country's mean DAS28 is (among others) confounded by regulations. Relatively strict prescription and reimbursement rules in the UK, a high SES country, result in a proportion of bDMARD-usage as
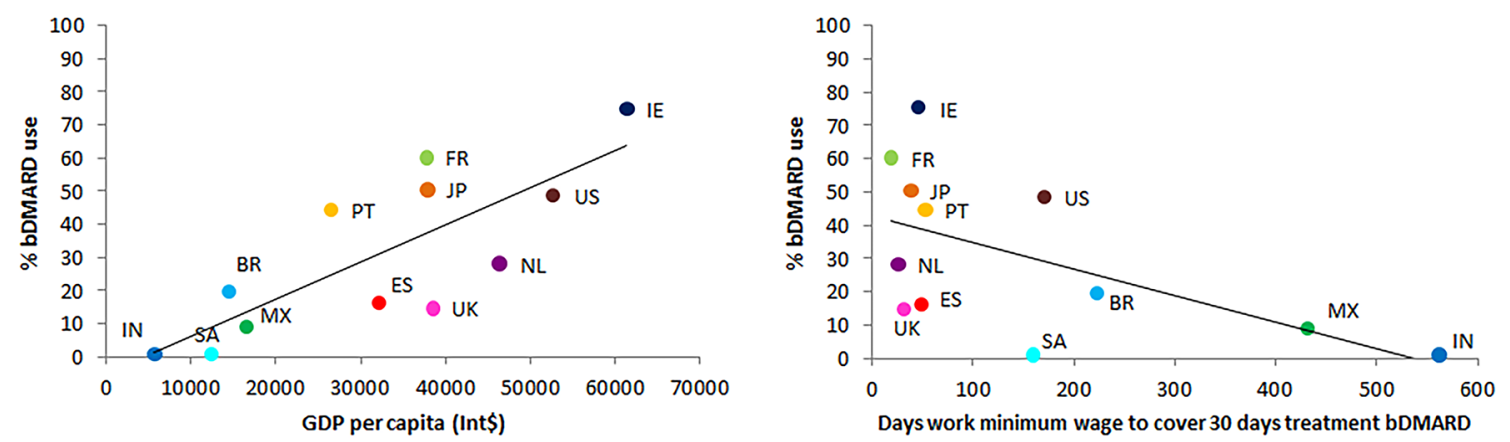

Figure 3 Associations between 'GDP per capita' and 'days to work at the minimum wage to cover 30 days of treatment with a bDMARD' with '\% bDMARD use'. bDMARD, biological disease modifying antirheumatic drugs; BR, Brazil; ES, Spain; FR, France; GDP, gross domestic product; IE, Ireland; IN, India; JP, Japan; MX, Mexico; NL, Netherlands; PT, Portugal; SA, SouthAfrica. 

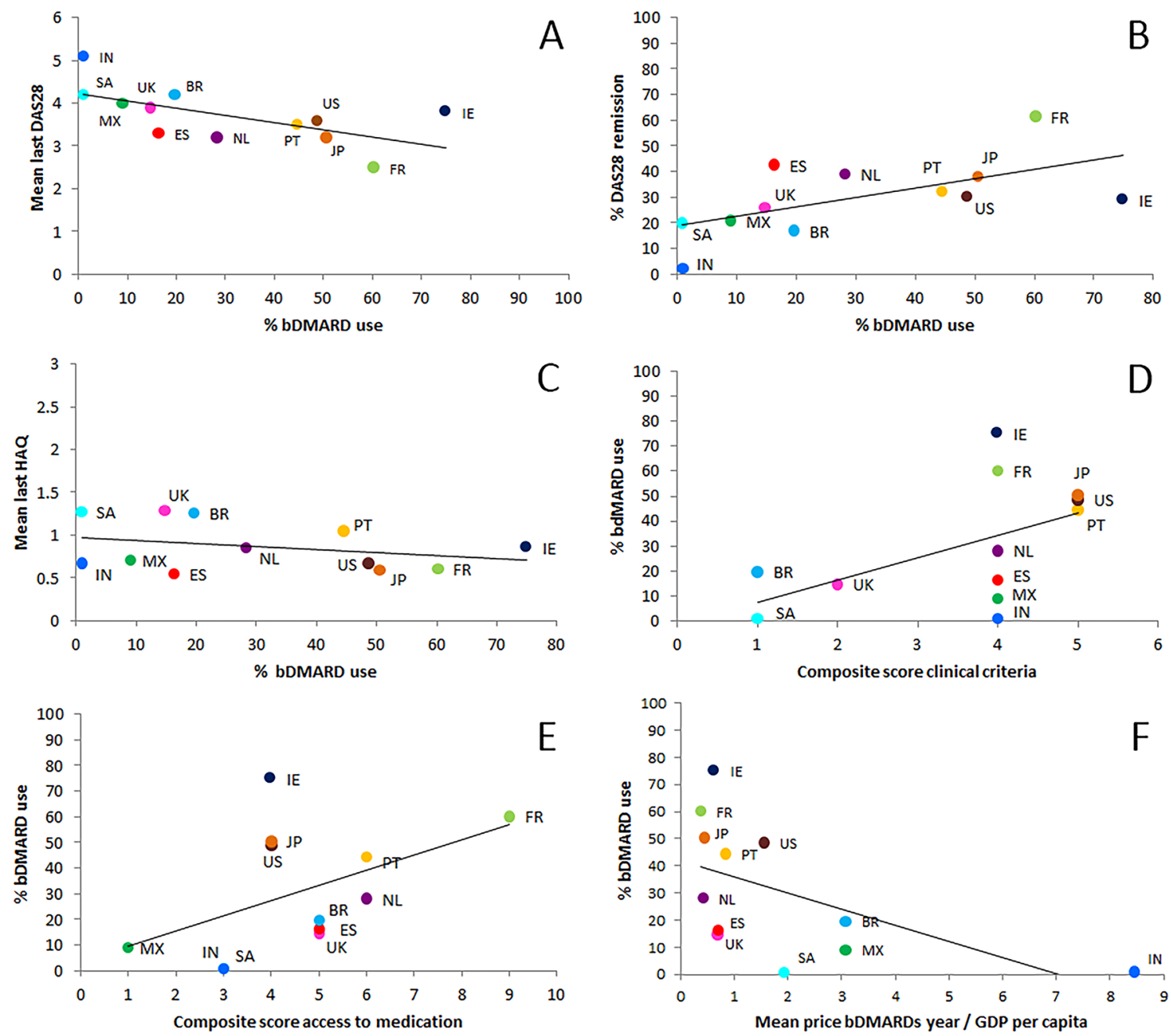

Figure 4 Associations between the '\% of patients that ever used a bDMARD' and the 'composite score clinical criteria', 'composite score access to medication' and clinical outcomes. bDMARD, biological disease modifying antirheumatic drugs; BR, Brazil; ES, Spain; FR, France; GDP, gross domestic product; IE, Ireland; IN, India; JP, Japan; MX, Mexico; NL, Netherlands; PT, Portugal; SA, South Africa.

low as in India and Mexico, which both have a low GDP per capita.

Finally, we calculated the quotient of a country's mean drugprice and the GDP per capita (as proxy for affordability, the lower the quotient, the less affordable the drug) and found (1) that even in countries with a same level of affordability (eg, EU countries) significant differences in bDMARD-usage exist, apparently due to other mechanisms than drug-prices alone and (2) that affordability of bDMARDs in some countries is so low that bDMARD-usage is virtually zero.

\section{Sensitivity analyses}

Sensitivity analyses using mixed modelling approaches to assess associations between SES (country level), bDMARD-use (country and patient level), disease activity and physical functioning (patient level) showed similar outcomes (online Supplementary file 5).

\section{DISCUSSION}

Worldwide, treatment options and clinical outcomes of patients with RA have greatly improved, but not all patients with RA have benefitted similarly. We hypothesised that differences in SES have an impact on bDMARD-usage and on clinical outcomes across countries. Indeed, in this study including a large number of patients from 12 countries, among which several countries that have never been investigated before in this context, we have found substantial differences in DMARDprices, affordability of these medications and bDMARD-usage across countries. We found that in countries with a lower SES disease activity was generally higher and bDMARD-usage was lower. But a country's proportion of bDMARD-usage was also associated with restrictions through prescription and reimbursement rules, and with affordability of bDMARDs, as defined by us.

It is attractive to assume that higher country's bDMARD-usage will result in a lower country's mean DAS28 and that a lower country's GDP will hinder a sufficiently high proportion of patients with RA getting proper access to care with bDMARDs. But reality is more complicated. The effectiveness of bDMARDusage in countries' all-day clinical practice may be overstated: previous research estimated that 'only' $7 \%$ of the effect of GDP per capita on DAS28 was mediated by the uptake of bDMARDs. ${ }^{4}$ We found 'only' $2.8 \%$ more patients in DAS28-remission for every additional $10 \%$ patients using a bDMARD. A positive effect of bDMARDs on RA treatment effectiveness thus appears to be quite small. Vice versa, this suggests that in low-income countries other factors than 'only' access to bDMARDs determine the success of RA treatment. Nevertheless, a general trend 
between countries' proportions of bDMARD-usage and countries' mean-DAS28 remains obvious.

Remarkably, we did not find an association between countries' SES and countries' mean HAQ-score. Here, the effect of outliers is relatively important. In particular, India, the country with lowest GDP, reported a low HAQ-score compared with a high DAS28. Moreover, there may be sociodemographic and cultural differences in the way patients experience or report limitations in function. ${ }^{1718}$ We could not assess the potential contribution of factors such as general access to healthcare and other drug and non-drug therapies, comorbidities and health barriers and support systems. ${ }^{19}$

Previous studies have mentioned associations between access to medication, SES and disease activity. ${ }^{61320}$ Such findings point to the negative effects of inequity: budget restrictions, strict regulations as well as limited access to drugs may be a hurdle for starting optimal treatment as recommended in clinical guidelines. ${ }^{1321}$

But this study also shows that several other factors play a role in determining the success of RA-treatment (here approximated by the countries' mean DAS28). We know several of these factors: countries' SES in general, the presence of a proper functioning healthcare system that may assure access to care to those who are in need, DMARD prices and valid national regulations that are in place to constrain the expenses for bDMARDusage. ${ }^{4-91321}$ It appears obvious that the country's mean level of DAS28 is the resultant of a complicated interplay of a country's SES, drug prices and regulations. In addition, it is difficult to argue that unlimited access to expensive effective treatments makes the difference between 'good and bad care' for patients with RA, nor can we claim that countries with similar GDP per capita or similar levels of access to care have similar proportions of patients on expensive bDMARDs; there is huge variation. Nevertheless, penetration of bDMARDs in low GDP-countries stays behind and it is to be expected that this-among othersmay go at the cost of effectiveness of RA care. It is impossible to conclude from this study whether this is due to drug prices, failing healthcare systems or simply worse access to optimal care. We can only conclude that there are substantial differences in mean DAS28 (as a proxy for quality of RA care) across countries.

This study has some strengths and many limitations. A strength of this study is that it captures real life clinical data from 12 countries worldwide with large differences in wealth, totally different (if any) healthcare and health-insurance systems and many patients with RA. As such, this study can be considered a 'big-data study' allowing subtle differences across countries to be elucidated.

But the strengths of our study (real life observational, size and international diversity) also carry limitations: case-ascertainment (cases cannot be verified), completeness of data (we had to statistically impute missing data) and reliability of data-points (we had to rely on the report of the participating physicians) are among them. Other epidemiological limitations are that only few centres per country participated and we had to assume that these centres were to some extent representative of the country. In addition, we had to make certain assumptions to facilitate computations, such as declaring bDMARD-reimbursement as 'absent', if according to the rheumatologist's questionnaires less than $20 \%$ of patients in a country had health insurance coverage. Furthermore, we used retail prices of bDMARDs, but final drug prices may be influenced by local and/or temporary discounts. Such assumptions-if flawed-may influence the reported associations. In a few cases, we relied on regional health-economical information rather than on country-specific data, in the appreciation that within a big country access to healthcare and regulations can be very different.

Moreover, differences between the patient samples from the included countries could potentially influence the associations that are investigated in this study. However, it is very unlikely that the available variables-which were all measured at a patient level-act as a confounder for the investigated associations. Therefore, we presented unadjusted models.

A final limitation of this database is that it will only include patients with RA that have come to the attention of the rheumatologist. If countries differ with regard to access to a rheumatologist, patients per country cannot be assumed to be comparable. Consequently, associations may be spurious. With regard to this latter argument, it can be postulated that the associations in this study are conservative and will likely be more exaggerated in real life.

Epidemiological limitations of 'big-data studies' restrict their interpretability. As such, causal interpretations will never be possible and should always be mistrusted. We have taken care to not exaggerate our conclusions that all remain at the level of associations and allow the possibility of bias and confounding as explanatory factors. In addition, we were interested in associations at the country level, but at the patient level results may be different. Still, 'big data studies' make sense in that they can point to relevant differences between countries, that may help policymakers to guide necessary change, pharmaceutical industry to direct market access and drug-prices and rheumatologists and healthcare workers to help improving access to rheumatology care.

In conclusion, we have documented using a registry of patients with RA spanning 12 countries worldwide that mean DAS28 as well as bDMARD-usage varies across countries. While we suggest an inverse relationship between the countries' bDMARD-usage and mean DAS28, this relationship is influenced by many other factors, including countries' GDP per capita, strictness of prescription and reimbursement rules and affordability of bDMARDs. Altogether these findings point to the existence of worldwide inequity with regard to optimal (access to) RA healthcare.

\section{Author affiliations}

Department of Rheumatology, Leiden University Medical Center, Leiden, The Netherlands

${ }^{2}$ Department of Rheumatology, CEDOC, Faculdade de Ciências Médicas, Universidade Nova de Lisboa, Lisbon, Portugal

${ }^{3} \mathrm{CHLO}$, EPE-Hospital Egas Moniz, Lisbon, Portugal

${ }^{4}$ Department of Rheumatology, Universidad Autonoma de Nuevo Leon, San Nicolas de los Garza, Mexico

${ }^{5}$ Rheumatology Center, UMass Memorial Medical Center, University of Massachusetts Medical School, Worcester, Massachusetts, USA

${ }^{6}$ Department of Rheumatology, University of the Witwatersrand, Johannesburg, South Africa

${ }^{7}$ Amsterdam Rheumatology and Immunology Center, Amsterdam, The Netherlands ${ }^{8}$ Zuyderland Medical Center, Heerlen, The Netherlands

Contributors $\mathrm{SAB}, \mathrm{CFA}$ and RBML contributed to the design, analysis and interpretation of the data. JCB, DV-M, KS-E, NG and CFA contributed to the acquisition of data. SAB drafted the work. All authors revised the manuscript and read and approved the final version of the document.

Funding The authors have not declared a specific grant for this research from any funding agency in the public, commercial or not-for-profit sectors.

Competing interests None declared.

Patient consent Not required.

Ethics approval The METEOR registry contains completely anonymised data which was gathered during daily practice. Treatment, timing of follow-up visits and measurements were unprotocolled. Therefore, medical ethics board approval was not required. 
Provenance and peer review Not commissioned; externally peer reviewed.

Data sharing statement The dataset used and analysed during the current study are available from the corresponding author on reasonable request.

\section{REFERENCES}

1 Quinn MA, Conaghan PG, Emery P. The therapeutic approach of early intervention for rheumatoid arthritis: what is the evidence? Rheumatology 2001;40:1211-20.

2 Nam JL, Ramiro S, Gaujoux-Viala C, et al. Efficacy of biological disease-modifying antirheumatic drugs: a systematic literature review informing the 2013 update of the EULAR recommendations for the management of rheumatoid arthritis. Ann Rheum Dis 2014;73:516-28

3 Smolen JS, Breedveld FC, Burmester GR, et al. Treating rheumatoid arthritis to target: 2014 update of the recommendations of an international task force. Ann Rheum Dis 2016;75:3-15.

4 Putrik P, Ramiro S, Keszei AP, et al. Lower education and living in countries with lower wealth are associated with higher disease activity in rheumatoid arthritis: results from the multinational COMORA study. Ann Rheum Dis 2016;75:540-6.

5 Smolen JS, Landewé R, Bij|sma J, et al. EULAR recommendations for the management of rheumatoid arthritis with synthetic and biological disease-modifying antirheumatic drugs: 2016 update. Ann Rheum Dis 2017;76:960-77.

6 Putrik P, Ramiro S, Kvien TK, et al. Variations in criteria regulating treatment with reimbursed biologic DMARDs across European countries. Are differences related to country's wealth? Ann Rheum Dis 2014;73:2010-21.

7 Emery P, Van Vollenhoven R, Ostergaard M, et al. Guidelines for initiation of antitumour necrosis factor therapy in rheumatoid arthritis: similarities and differences across Europe. Ann Rheum Dis 2009;68:456-9.

8 Orlewska E, Ancuta I, Anic B, et al. Access to biologic treatment for rheumatoid arthritis in Central and Eastern European (CEE) countries. Med Sci Monit 2011;17:SR1-13.

9 Pease C, Pope JE, Truong D, et al. Comparison of anti-TNF treatment initiation in rheumatoid arthritis databases demonstrates wide country variability in patient parameters at initiation of anti-TNF therapy. Semin Arthritis Rheum 2011;41:81-9.
10 Laires PA, Exposto F, Mesquita R, et al. Patients' access to biologics in rheumatoid arthritis: a comparison between Portugal and other European countries. Eur $\mathrm{J}$ Health Econ 2013;14:875-85.

11 Bergstra SA, Machado PM, van den Berg R, et al. Ten years of METEOR (an international rheumatoid arthritis registry): development, research opportunities and future perspectives. Clin Exp Rheumatol 2016;34:S87.

12 Schafer JL. Analysis of Incomplete Multivariate Data. Boca Raton, FL: Chapman \& Hall/CRC, 1997.

13 Putrik P, Ramiro S, Kvien TK, et al. Inequities in access to biologic and synthetic DMARDs across 46 European countries. Ann Rheum Dis 2014;73:198-206.

14 List of minimum wages by country. https://en.wikipedia.org/wiki/List_of_minimum_ wages_by_country

15 The World Bank. http://www.worldbank.org/ (accessed 24-05-2017).

16 OECD. OECD Better Life Index: Income. http://www.oecdbetterlifeindex.org/topics/ income/ (accessed 24-05-2017).

17 Hifinger M, Norton S, Ramiro S, et al. Equivalence in the Health Assessment Questionnaire (HAQ) across socio-demographic determinants: Analyses within QUESTRA. Semin Arthritis Rheum 2018:47.

18 Putrik P, Ramiro S, Hifinger M, et al. In wealthier countries, patients perceive worse impact of the disease although they have lower objectively assessed disease activity: results from the cross-sectional COMORA study. Ann Rheum Dis 2016;75:715-20.

19 van den Hoek J, Roorda LD, Boshuizen HC, et al. Physical and Mental Functioning in Patients with Established Rheumatoid Arthritis over an 11-year Followup Period: The Role of Specific Comorbidities. J Rheumatol 2016;43:307-14.

20 Putrik P, Ramiro S, Chorus AM, et al. Socioeconomic inequities in perceived health among patients with musculoskeletal disorders compared with other chronic disorders: results from a cross-sectional Dutch study. RMD Open 2015;1:e000045.

21 Guillemin F, Carruthers E, Li LC. Determinants of MSK health and disability-social determinants of inequities in MSK health. Best Pract Res Clin Rheumatol 2014;28:411-33 